Dhaka Univ. J. Biol. Sci. 19(2): 129-135, 2010 (July)

\title{
ANTIGENICITY OF THE SURFACE PROTEINS OF NON O1 NON 0139 VIBRIO CHOLERAE IN RABBIT MODEL
}

\author{
Tania S. Bonny, Fazle Rabi, Mahmuda Yasmin, Jamalun Nessa \\ AND CHOWDHURY R. AHSAN* \\ Department of Microbiology, University of Dhaka, Dhaka-1000, Bangladesh
}

Key words: Antigenicity, Surface proteins, Non O1 non O139 V. cholerae, Rabbit model

\begin{abstract}
An investigation was carried out to demonstrate the antigenicity of the surface proteins of the non $\mathrm{O} 1$ non $\mathrm{O} 139 \mathrm{~V}$. cholerae in rabbit model. Three rabbits were immunized with the surface proteins and sera were collected at one week intervals for six weeks. Sera were examined for antibodies specific for surface antigens using ELISA and the results showed a significant increase in antibody titers with time. The SDS-PAGE analysis showed a number of protein bands ranging from 21 to $131 \mathrm{kDa}$ after Coomassie brilliant blue R250 staining. However, immunoblot analysis showed four major antigenic bands of 38, 43, 74 and $85 \mathrm{kDa}$ to be prominent. These identified proteins might have higher immunogenic effects among humans infected with non $\mathrm{O} 1$ non $\mathrm{O} 139 \mathrm{~V}$. cholerae and some of these antigenic proteins could be included as diagnostic tools based on serology and also in vaccine preparations.
\end{abstract}

\section{Introduction}

The non $\mathrm{O} 1$ non $\mathrm{O} 139$ serogroups of $V$. cholerae comprise a heterogeneous group of organisms whose clinical association with humans is inadequately understood.(1) In a recent study of present authors reported that the non $\mathrm{O} 1$ non $\mathrm{O} 139 \mathrm{~V}$. cholerae lacked the ctx and zot genes but produced an enterotoxin, which is antigenically different from the known cholera toxin and caused fluid accumulation in rabbit ileal loops. ${ }^{(2)}$ On the other hand, recent studies revealed the induction of a stable immune response and/or successful protection in mice after immunization of the animals with outer membrane vesicles derived from Salmonella enterica serovar Typhimurium or Helicobacter pylori.(3-4) Outer membrane vesicles largely reflect the composition of the outer membranes and periplasm of the bacteria and thus the vesicles provide high concentrations of many of the most important surface antigens for immunization. Several factors of $V$. cholerae have also been demonstrated to be important for intestinal adhesion, colonization or even protection. A large number of these factors are associated with the outer membrane proteins (OMPs), outer membrane porins, toxin-corregulated pilus, flagella, lipopolysaccharides or outer membrane vesicles, which are known not only to be highly immunogenic and to have qualities as adjuvants but also to provide in most cases a strain-specific immune response. ${ }^{(5-10)}$

*Corresponding author: Department of Microbiology, University of Dhaka, Dhaka 1000, Bangladesh. E-mail: crahsan@univdhaka.edu 
In this study attempt has been made to investigate the immune response of the surface proteins of the non $\mathrm{O} 1$ non $\mathrm{O} 139 \mathrm{~V}$. cholerae bacteria in rabbit model to better understand the antigenicity of the surface proteins and their relationship with other O1 or non $\mathrm{O} 1 \mathrm{~V}$. cholerae surface antigens.

\section{Materials and Methods}

The non $\mathrm{O} 1$ non $\mathrm{O} 139 \mathrm{~V}$. cholerae, which was originally isolated from a small water reservoir around Dhaka city, was collected from the stock culture of the Department of Microbiology, University of Dhaka. The collected strain (MT-25) was confirmed again by slide agglutination test using specific $\mathrm{O} 1$ and $\mathrm{O} 139$ antisera.

Surface proteins of the non $\mathrm{O} 1$ non $\mathrm{O} 139 \mathrm{~V}$. cholerae were extracted following the method described by Ahsan and Sasaki.(11)

Three New Zealand white female rabbits (1.5 - $2.0 \mathrm{~kg}$ body weight) were used for this study, which were housed with adequate food and freshwater. A great care was taken in cleaning and maintenance of hygienic conditions during the study.

Using a 22G needle, all rabbits were immunized at days 0, 20, 35 and 45 with the surface proteins of the non $\mathrm{O} 1$ non $\mathrm{O} 139 \mathrm{~V}$. cholerae strain via intramuscular route. The first and second doses (50 $\mathrm{\mu g}$ protein/ $\mathrm{kg}$ body weight) were administered with adjuvant mixtures (Freund's incomplete and Freund's complete adjuvant, respectively). Saline was used as the diluent for the rest of the doses $(25 \mu \mathrm{g}$ protein $/ \mathrm{kg}$ body weight). Sera (approximately $5 \mathrm{ml}$ ) collected from the rabbits before immunizations, served as negative controls.

During the whole immunization period, blood was collected from the marginal ear veins at one week intervals to check the immune response of the surface proteins. Final blood was collected by cardiac puncture six days after the last booster dose. Sera were aseptically separated from blood samples, aliquoted and stored at $-20^{\circ} \mathrm{C}$ for further analysis.

Antibody titers of the sera against surface proteins were determined by Enzyme Linked Immunosorbent Assay (ELISA) using a 96 - well ELISA microtiter plate (BD Falcon).(12)

The surface proteins were subjected to SDS-PAGE ${ }^{(13)}$ analysis where gels were comprised of $5 \%$ stacking and $10 \%$ separating gels. Electrophoresis was performed at a constant current of $15 \mathrm{~mA}$ for $2-2.5 \mathrm{hr}$ and the proteins bands in the gels were then stained with $0.1 \%$ Coomassie brilliant blue R250. In the Western blot analysis, the proteins in gel were transferred to a nitrocellulose membrane ${ }^{(14)}$ using a semidry electrotransfer apparatus (Bio-Rad) and nonspecific binding sites were blocked with 3\% skimmed milk in PBS (PBS-S) for $2 \mathrm{hr}$ at room temperature. After three times washing with $0.1 \%$ Tween in PBS (PBS-T), the membrane was incubated with rabbit sera (collected six days after the last booster dose) at a dilution of $1: 100$ in PBS-S for $2 \mathrm{hr}$ at room 
temperature. Following washing again with PBS-T, the membrane was incubated with alkaline phosphatase conjugated goat anti-rabbit antibody (whole molecule; Sigma, USA) diluted at $1: 10,000$ in PBS-S for $1 \mathrm{hr}$ at room temperature. After washing again with PBS$\mathrm{T}$, the membrane was dipped in the substrate solution [comprising of $2 \mathrm{ml}$ of $0.1 \mathrm{M}$ Tris, 2 $\mathrm{ml}$ of $0.09 \mathrm{M} \mathrm{NaCl}, 6 \mathrm{ml}$ of $0.15 \mathrm{M}$ magnesium chloride, $44 \mu \mathrm{l}$ of NBT (nitrobluetetrazolium) and $33 \mu \mathrm{l}$ of BCIP (5-bromo, 4-chloro, 3-indolylphosphate)] until the antigenic bands had appeared. The reaction was stopped by washing the membrane in water several times.

\section{Results and Discussion}

In this study, the objective was to observe the long term systemic immunogenicity of the surface proteins of the non $\mathrm{O} 1$ non $\mathrm{O} 139 \mathrm{~V}$. cholerae in the rabbit model. Therefore, the authors tried to evaluate the IgG response only of the animals against the surface proteins using ELISA technique, where anti-rabbit IgG (whole molecule) HRP conjugate developed in goat was used as secondary antibody. The sera collected from three rabbits for six weeks were examined and the ELISA values $\left(\mathrm{OD}_{490}\right)$ from all dilutions showed presence of adequate amounts of anti- non $\mathrm{O} 1$ non $\mathrm{O} 139 \mathrm{~V}$. cholerae antibody. The negative control sera collected from the rabbits on day 0 before immunization with the surface antigens showed no antibodies against the non $\mathrm{O} 1$ non $\mathrm{O} 139 \mathrm{~V}$. cholerae surface proteins. Using ELISA values for $1: 50$ dilution on different days $(7,14,21,28,35,42)$ a plot of antibody titer versus time was drawn (Fig. 1). Similar results were obtained from

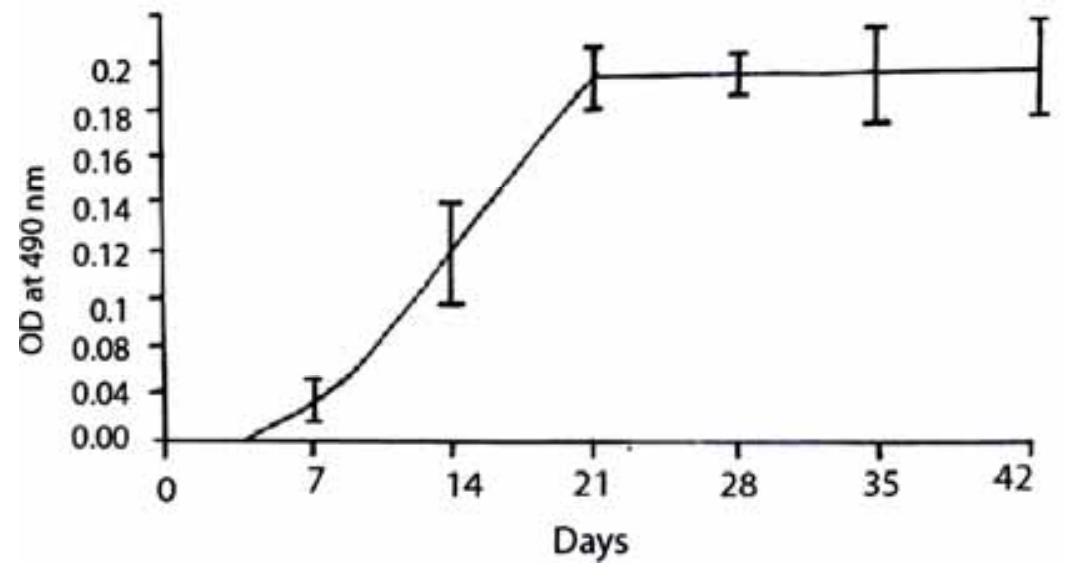

Fig. 1. Kinetics of anti- non $\mathrm{O} 1$ non $\mathrm{O} 139 \mathrm{~V}$. cholerae surface protein antibody responses in rabbits.

Bar at each point shows mean $\pm \mathrm{Sd}$.

other dilutions (Neat, $1: 100,1: 200,1: 400$, and $1: 800$ ) (data not shown). The graph showed a significant increase in anti non $\mathrm{O} 1$ non $\mathrm{O} 139 \mathrm{~V}$. cholerae antibody with time. After immunization, the production of antibody increased almost exponentially up to day 21 and after that, it maintained the same level until the last day. 
In the SDS-PAGE, a number of protein bands ranging from 21 to $131 \mathrm{kDa}$, were obtained. Among them, 38, 43, 74, 76 and $85 \mathrm{kDa}$ protein bands were more prominent (Fig. 2). The surface proteins were extracted following an established water extraction method, ${ }^{(11)}$ which removes the surface structures like outer membrane proteins, lipopolysaccharides, glycolproteins, or other components from the cells. In this study, the water extracted materials were analyzed by the SDS-PAGE and later on stained with Coomassie Brilliant blue R250, which specifically stained the protein bands. These also indicate that the bands of interest in the SDS-PAGE or the bands on the nitrocellulose membrane are components of the surface proteins. Again, the surface proteins were extracted from the isolates by a mild water extraction method which did not employ chemicals like urea or high concentration of SDS, which are likely to denature or distort protein conformation and break down multimeric proteins into monomers. Therefore, the proteins bands thus observed are most likely the undisturbed surface protein of the bacteria.

\section{Lane-1 Lane-2}

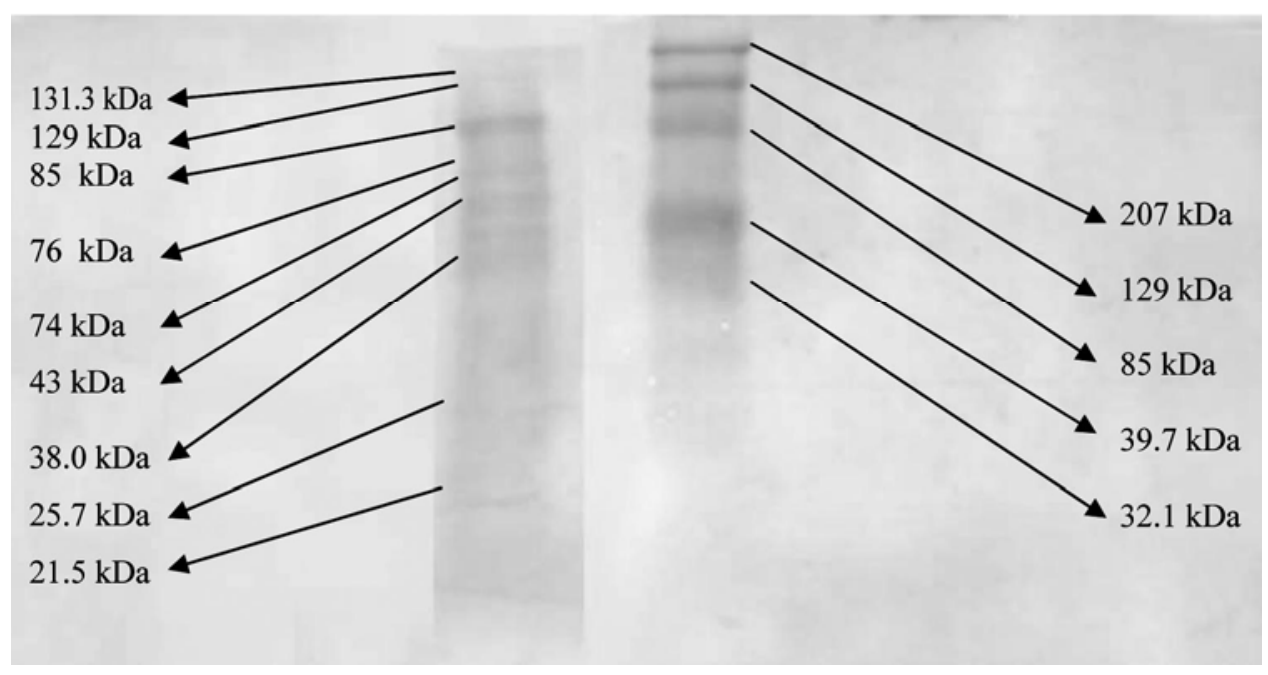

Fig. 2. Protein profile of the surface proteins of non O1 non O139 V. cholerae (Lane 1) after SDSPAGE analysis following Coomassie brilliant blue R250 staining of the gel. Several bands of different molecular weights ( 21 to $131 \mathrm{kDa}$ ) were prominent on the gel. Arrows on the left and the right side indicate the molecular masses of the proteins in $\mathrm{kDa}$. Lane 2 is the molecular weight marker (Myosin, $207 \mathrm{kDa} \beta$-galactosidase, $129 \mathrm{kDa}$; Bovine serum albumin, $85 \mathrm{kDa}$; Carbonic anhydrase, $39.7 \mathrm{kDa}$; Soybean trypsin inhibitor, $32.1 \mathrm{kDa})$.

The reactivity of the antisera to the surface proteins of the non $\mathrm{O} 1$ non $\mathrm{O} 139 \mathrm{~V}$. cholerae was tested by immunoblotting. The antisera recognized predominantly four major proteins of 38, 43, 74 and $85 \mathrm{kDa}$ (Fig. 3). However, other proteins of $<38 \mathrm{kDa}$ and $>85 \mathrm{kDa}$ also reacted weakly with the antisera. Similar results were also reported by 
other workers ${ }^{(5)}$, who showed the major outer membrane antigenic proteins of the $V$. cholerae $\mathrm{O} 1$ and non $\mathrm{O} 1$ serovars to be 38 and $43 \mathrm{kDa}$. In addition to the above proteins, there might be other antigenically common surface proteins in non 01 non O139 $\mathrm{V}$. cholerae, although these were probably less immunogenic, at least in rabbits.
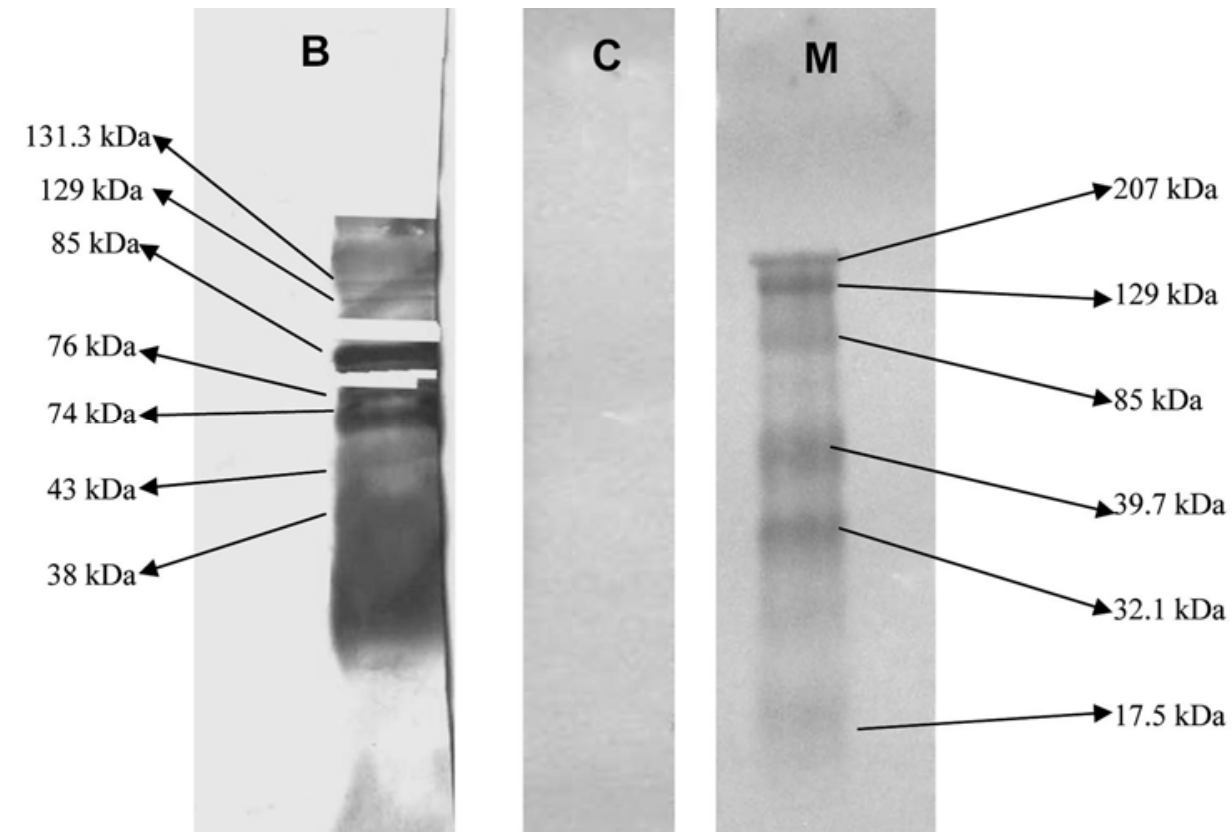

Fig. 3. Immunoblot analysis of the antibody reactivity in sera from immunized rabbits. Shown are a representative immunoblot loaded with surface proteins of the non $\mathrm{O} 1$ non $\mathrm{O} 139 \mathrm{~V}$. cholerae and incubated with serum collected at day 51 from the immunized rabbit (Lane 1). Several antigenic bands ranging from 38 and $131 \mathrm{kDa}$ were prominent on the membrane. Membrane incubated with the control serum did not show any band (Lane 2). Lane 3 shows the known molecular weight marker. Arrows on the left and the right side indicate the molecular masses of the proteins in $\mathrm{kDa}$.

A large number of different proteins present on the surface of $V$. cholerae may play major antigenic roles in infection. ${ }^{(5-11)}$ The finding that antibodies to OMPs could inhibit, albeit partially, the intestinal adhesion of $V$. cholerae supports this view.(5) Other results also suggest that some of the OMPs critical for adhesion are immunogenic and probably shared by $V$. cholerae strains irrespective of biotype, serotype and serovar. However, inability of anti-OMPs sera to completely inhibit the intestinal attachment of $V$. cholerae is indicative of the possible involvement of non-OMP components in the adhesion process. The complex pathogenesis of this infection in the host demands better approaches to the identification of novel immunogens that would give substantial protection. The identified proteins might have higher immunogenic effects among humans infected with 
non $\mathrm{O} 1$ non $\mathrm{O} 139 \mathrm{~V}$. cholerae and some of these immunogenic proteins could be included as diagnostic tools based on serology and also in vaccine preparation. ${ }^{(15)}$ However, further characterizations of these antigenic proteins are necessary.

\section{References}

1. Mukhopadhyay AK, S Garg, R Mitra, A Basu, D Dutta, SK Bhattacharya, T Shimada, T Takeda, Y Takeda and GB Nair 1996. Temporal shifts in traits of $V$. cholerae strains isolated from hospitalized patients in Calcutta: A three year (1993 to 1995) analysis. J. Clin. Microbiol. 34: 2537-2547.

2. Begum K, CR Ahsan, M Ansaruzzaman, DK Dutta, , QS Ahmad and KA Talukder 2006. Toxin(s), other than cholera toxin, produced by environmental non O1 non O139 Vibrio cholerae. Cell. Mol. Immunol. 3: 115-21.

3. Alaniz RC, BL Deatherage, JC Lara and BT Cookson 2007. Membrane vesicles are immunogenic facsimiles of Salmonella typhimurium that potently activate dendritic cells, prime B and T cell responses, and stimulate protective immunity in vivo. J. Immunol. 179: 7692-7701.

4. Keenan J, T Day, S Neal, B Cook, G Perez-Perez, R Allardyce and P Bagshaw 2000. A role for the bacterial outer membrane in the pathogenesis of Helicobacter pylori infection. FEMS Microbiol. Lett. 182: 259-264.

5. Sengupta D, K Datta-Roy, K Banerjee and AC Ghose 1989. Identification of some antigenically related outer-membrane proteins of strains of Vibrio cholerae $\mathrm{O} 1$ and non-O1 serovars involved in intestinal adhesion and the protective role of antibodies to them. J. Med. Microbiol. 29: 33-39.

6. Provenzano D and KE Klose 2000. Altered expression of the ToxR-regulated porins OmpU and OmpT diminishes Vibrio cholerae bile resistance, virulence factor expression, and intestinal colonization. Proc. Natl. Acad. Sci. USA 97: 10220-10224.

7. Thelin KH and RK Taylor 1996. Toxin-coregulated pilus, but not mannose-sensitive hemagglutinin, is required for colonization by Vibrio cholerae O1 El Tor biotype and O139 strains. Infect. Immun. 64: 2853-2856.

8. Yancey RJ, DL Willis and LJ Berry 1978. Role of motility in experimental cholera in adult rabbits. Infect. Immun. 22:387-392.

9. Vijayashree S, N Nayak, D Panigrahi and S Sehgal 2003. Role of cell surface antigens of Vibrio cholerae $\mathrm{O} 1$ and non $\mathrm{O} 1$ serovars in intestinal adhesion. Indian J. Pathol. Microbiol. 46: $259-260$

10. Schild S, EJ Nelson and A Camilli 2008. Immunization with Vibrio cholerae outer membrane vesicles induces protective immunity in mice. Infect. Immun. 76: 4554-4563.

11. Ahsan CR and J Sasaki 1991. A $64 \mathrm{kDa}$ protein from Mycobacterium bovis BCG shares the same antigenic determinants with line 10 hepatoma cells and has anti-line 10 tumor activity. FEBS Lett. 288: 77-80.

12. Sack DA, S Huda, PK Neogi, RR Daniel and WM Spira 1980. Microtiter ganglioside enzymelinked immunosorbent assay for Vibrio and Escherichia coli heat-labile enterotoxins and antitoxin. J. Clin. Microbiol. 11(1): 35-40. 
13. Laemmli UK 1970. Cleavage of structural proteins during the assembly of the head of bacteriophage T4. Nature 227: 680-685.

14. Towbin $\mathrm{H}$ and J Gordon 1984. Immunoblotting and dot immunoblotting-current status and outlook. J. Immunol. Methods 72: 313-340.

15. Schild S, EJ Nelson, AL Bishop and A Camilli 2009. Characterization of Vibrio cholerae Outer Membrane Vesicles as a Candidate Vaccine for Cholera. Infect. Immun. 77: 472-484.

(Manuscript received on 6 October, 2009; revised on 15 June, 2010) 